\title{
Concurrent chemoradiotherapy using paclitaxel plus cisplatin in the treatment of elderly patients with esophageal cancer
}

This article was published in the following Dove Press journal:

OncoTargets and Therapy

22 October 2015

Number of times this article has been viewed

\author{
Tao Songl,* \\ Xuebang Zhang ${ }^{2, *}$ \\ Min Fang' \\ Shixiu Wu' \\ 'Department of Radiation Oncology, \\ Hangzhou Cancer Hospital, Hangzhou, \\ Zhejiang, People's Republic of \\ China; ${ }^{2}$ Department of Radiation \\ Oncology, The First Affiliated Hospital \\ of Wenzhou Medical University, \\ Wenzhou, Zhejiang, People's Republic \\ of China \\ *These authors contributed equally to \\ this work
}

Objective: This study aimed at assessing the efficiency and safety of concurrent chemoradiotherapy (CCRT) using paclitaxel (PTX) plus cisplatin (CDDP) in elderly (age $\geq 70$ years) esophageal cancer patients.

Patients and methods: Between July 2008 and June 2011, 82 esophageal cancer patients aged $\geq 70$ years were retrospectively analyzed. Chemotherapy consisted of CDDP for 3 days plus PTX given for 3 hours. The preplanned total dose of concurrent irradiation with $60 \mathrm{~Gy} / 30$ Fx was given at the 1 st day of chemotherapy.

Results: The average age for the enrolled patients was 76.41 years (range: 70-87 years), and the clinical stages were stage I (two patients), stage II (23 patients), stage III (49 patients), and stage IV (eight patients). A total of 66 patients finished CCRT on schedule, including 55 (67.1\%) patients in whom treatment regimen was not changed, and the clinical complete response was achieved in 29 patients. With a median follow-up time of 20.4 months, the median overall survival (OS) time and progression-free survival (PFS) time were 26.9 months and 18.2 months, respectively. The 2-year OS and PFS rates for stage I-II and III-IV were $76.0 \%, 64.0 \%$ and $38.6 \%, 21.2 \%$, respectively. Grade $\geq 3$ leukopenia was observed in 25 patients, and the most common nonhematologic toxicity was esophagitis including five and two patients with grade 3 and 4, respectively. Multivariate analysis revealed that clinical stage was a strong factor for OS and PFS.

Conclusion: CCRT using PTX plus CDDP for selected elderly esophageal cancer patients resulted in encouraging survival outcomes and tolerable toxicities. Future prospective studies in large cohorts are highly warranted to confirm the findings in our report.

Keywords: esophageal cancer, elderly, concurrent chemoradiotherapy, paclitaxel, survival, toxicity

\section{Introduction}

Esophageal cancer remains one of the most fatal cancers worldwide (representing 7\% of all gastrointestinal cancers internationally). The overall 5-year survival rate for all patients with esophageal cancer is no better than a mere $20 \%,{ }^{1,2}$ and it is estimated that over $20 \%$ of patients with esophageal cancer are diagnosed at an elderly age. ${ }^{3}$ Traditionally, esophagectomy plays the pivotal role for the treatment of early-stage and localized esophageal cancer, but it is less frequently performed in elderly patients. A series of reports had revealed that postoperative mortality rates in patients aged $\geq 70$ years ranged from $4.5 \%$ to $23 \%$ and may even reach $60 \% .{ }^{4-6}$ Concurrent chemoradiotherapy (CCRT) has also been considered as the standard treatment option for patients with inoperable or unresectable diseases, for which elderly patients account for a great proportion as established by the landmark results of Radiation Therapy Oncology Group (RTOG) 8501.7 A combination of fluorouracil (5-FU) and cisplatin (CDDP) has also been confirmed as a standard
Department of Radiation Oncology, Hangzhou Cancer Hospital, Number 34, Yanguan Lane, Shangcheng District, Hangzhou 310000 , People's Republic of China

Tel +8657186826086

Fax +86 57। 8606228 I

Email wushixiu@medmail.com.cn 
radiosensitizing chemotherapy regimen since then. However, the efficacy of this regimen was only approximately $25 \%-35 \%$, and the median survival time was no better than 16 months in advanced esophageal cancer patients. ${ }^{7,8}$ Thus, exploring other potent radiosensitizers and more effective and tolerable anticancer drugs in elderly patients are gaining momentum.

Paclitaxel (PTX), a broad-spectrum cytotoxic drug, is a promising agent against esophageal cancer. Preclinical studies had shown that PTX can enhance radiation sensitivity of tumor cells, potentiate tumor response, and increase the therapeutic ratio of radiotherapy. ${ }^{9}$ Clinical trials had also revealed that substituting PTX for 5-FU and combining with CDDP had achieved better efficacy in a neoadjuvant and definitive setting for advanced esophageal cancer, and the effective rate was approximately $50 \%-60 \%$ with a more favorable toxicity profile, ${ }^{10-12}$ which was also validated in our cancer center. ${ }^{13}$ But, to our knowledge, no specific data have been published regarding the regimes of PTX and CDDP (TP regime) combined with radiotherapy in the setting of CCRT for elderly esophageal cancer patients.

Based on this background, we performed a retrospective study to investigate the feasibility and efficiency of CCRT with PTX and CDDP for elderly esophageal cancer patients treated in our cancer center. We defined an elderly population as persons aged $\geq 70$ years, according to a series of recent studies. ${ }^{3,14-16}$

\section{Patients and methods}

\section{Patients work-up}

Between July 2008 and June 2011, 248 consecutive patients with newly diagnosed esophageal cancer underwent CCRT at the cancer center of Wenzhou Medical University. Of these patients, $82(33.1 \%)$ patients aged over 70 years were retrospectively reviewed. This study was approved by the Institutional Review Boards of Wenzhou Medical University, and patients' records were anonymized and deidentified prior to analysis. The main reasons for indication of CCRT and/or contraindication of surgery were rejection of surgery $(n=19)$ or no indication of surgery because of advanced age $(n=16)$, lower Eastern Cooperative Oncology Group (ECOG) performance status (PS) $(n=18)$, severe comorbidity $(n=14)$, or tumor location (cervical esophagus) $(n=15)$.

Criteria for inclusion in our study included 1) histological diagnosis of esophageal cancer; 2) clinical stages I-IV disease according to the International Union Against Cancer (UICC, 2002) TNM stage criteria; 3) ECOG PS of at least 2; 4) no evidence of severe organ dysfunction; 5) adequate bone marrow, renal, hepatic, cardiac, and respiratory function (white blood cell $>3,000 / \mu \mathrm{L}$, platelet counts $>10 \times 10^{4} / \mu \mathrm{L}$, serum creatinine $<1.5 \mathrm{mg} / \mathrm{dL}$ ); and 6) no prior chest radiation or chemotherapy received. Patient's baseline characteristics (dysphagia, weight loss, albumin, hemoglobin, comorbidities) were also collected. Degree of dysphagia was evaluated using the Atkinson score, ${ }^{17}$ and the Charlson score was adopted for the analysis of patient's comorbidities, which was based on 19 medical conditions. ${ }^{18}$

\section{Treatment schedule and dose modification}

PTX $\left(135 \mathrm{mg} / \mathrm{m}^{2}\right)$ was administered intravenously over 3 hours on day 1 and day 29 with standard premedications. CDDP (30 mg/m²) was administered as an intravenous infusion on days 1-3 and days 29-31. Radiotherapy was given concurrently on the 1st day of the first cycle of chemotherapy (Figure 1). The gross tumor volume (GTV) received 60 Gy (30 fractions at 2 Gy per fraction) and clinical target volume (CTV) was 40 Gy (20 fractions at 2 Gy per fraction). Radiotherapy was delivered in three-dimensional conformal technique, and no intensity-modulated radiotherapy was used. The definition of GTV, CTV, and dose-volume constraints of normal tissue in our institute has been described previously. ${ }^{13,19}$

Chemotherapy was delayed for acute toxicities until recovery to grade $\leq 1$, and/or the dose was reduced for grade 3 or higher hematological toxicity. PTX was reduced to $80 \%$ in the second course if any of the following occurred: grade 3 neutropenia with fever or grade 4 neutropenia. Granulocyte colonystimulating factor (G-CSF) was used to treat for the occurrence of febrile neutropenia. If the creatinine clearance decreased to less than $50 \mathrm{~mL} / \mathrm{min}$, the CDDP dose was also reduced to $80 \%$. Irradiation was interrupted for grade $\geq 3$ esophagitis, grade 3 neutropenia with fever, or grade 4 neutropenia. Radiation therapy was restarted when toxicities recovered to grade $\leq 2$.

\section{Evaluation and follow-up}

All the patients were hospitalized and monitored weekly during the treatment course for acute treatment toxicity.

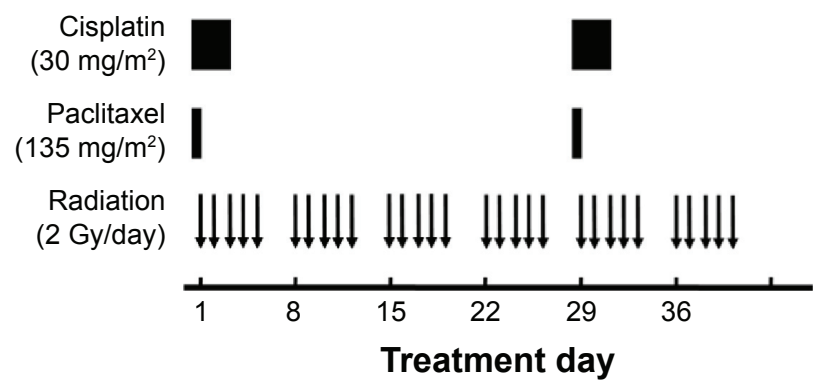

Figure I Treatment scheme. 
Physician-reported hematological, esophageal, and pulmonary toxicities were evaluated according to the common toxicity criteria for adverse events version 3.0. Clinical response was assessed according to Response Evaluation Criteria in Solid Tumors system 4 weeks after the completion of treatment, and follow-up was regularly carried out at 3-month interval in the first 2 years and at 6-month interval after 2 years. Treatment failure was defined as any sign of recurrent disease, which could be local, distant, or both. And, we also assessed failure models by posttreatment esophagogram, endoscopy, computed tomography (CT), or integrated positron emission tomography/CT (if available) scans and compared those data with the original CT-based radiation treatment plans.

\section{Statistical analysis}

All the statistical analyses were performed using SPSS version 16.0 software (SPSS Inc., Chicago, IL, USA). Overall survival (OS) was determined as the time (in months) between the 1st day of therapy and the last follow-up or the date of death. Progression-free survival (PFS) was calculated from the date of CCRT initiation to the date of documented failure (local recurrence or metastasis occurrence) or the date of the last follow-up for those still alive. Survival curves were determined using the Kaplan-Meier method. Given that a small portion of our raw data $(<5 \%)$ was considered as missing data, we imputed these missing data with mean substitution. Predictive factors of survival were analyzed by a univariate analysis and further evaluated by multivariate Cox regression analysis to estimate the hazard ratio with 95\% confidence interval (CI). All statistical analyses were performed with a two-sided significance value of 0.05 .

\section{Results}

\section{Patients and tumor characteristics}

A total of 82 patients were eligible for analysis. Clinical baseline characteristics are detailed in Table 1 . The mean age was 76.41 years, ranging from 70 to 87 years. Sixty-seven patients were male and 15 were female, with a sex ratio of 4.5:1.0; majority of patients (76.8\%) had a good ECOG PS score (0-1). Approximately $36.6 \%$ patients had a severe dysphagia $\geq 2$, and $30.5 \%$ had an initial weight loss $>10 \%$ in 6 months. The median Charlson score was 2, and the most common comorbidity for this cohort was hypertension $(\mathrm{n}=37)$. Diabetic (30.5\%) and peripheral vascular or cerebrovascular disease $(12.2 \%)$ were ranked second and third in the data.

Detailed tumor characteristics before treatment are listed in Table 2. There were mainly $\mathrm{T}_{3-4}$ stage tumors (92.7\%)
Table I Pretreatment characteristics of the 82 elderly patients

\begin{tabular}{|c|c|c|}
\hline \multirow[t]{2}{*}{ Characteristics } & \multicolumn{2}{|c|}{$\mathrm{N}=82$} \\
\hline & $\mathbf{N}$ & Percentage \\
\hline \multicolumn{3}{|l|}{ Age (years) } \\
\hline Average (SD, min-max) & \multicolumn{2}{|c|}{$76.4 \mathrm{I}(5.20,70-87)$} \\
\hline $70 \leq$ age $<75$ & 39 & 47.6 \\
\hline $75 \leq$ age $<80$ & 21 & 25.6 \\
\hline Age $\geq 80$ & 22 & 26.8 \\
\hline \multicolumn{3}{|l|}{ Sex } \\
\hline Female & 15 & 18.3 \\
\hline Male & 67 & 81.7 \\
\hline \multicolumn{3}{|l|}{ ECOG performance status } \\
\hline $0-1$ & 63 & 76.8 \\
\hline 2 & 19 & 23.2 \\
\hline \multicolumn{3}{|l|}{ Weight loss in 6 months } \\
\hline$\leq 10 \%$ & 57 & 69.5 \\
\hline$>10 \%$ & 25 & 30.5 \\
\hline \multicolumn{3}{|l|}{ Charlson comorbidity score } \\
\hline $0-1$ & 27 & 32.9 \\
\hline$\geq 2$ & 55 & 67.1 \\
\hline \multicolumn{3}{|l|}{ Albumin $(g / L)$} \\
\hline$\geq 30$ & 75 & 91.5 \\
\hline$<30$ & 7 & 8.5 \\
\hline \multicolumn{3}{|l|}{ Hemoglobin (g/L) } \\
\hline$\geq 10$ & 55 & 67.1 \\
\hline $8 \leq \mathrm{Hb}<10$ & 18 & 22.0 \\
\hline$<8$ & 9 & 10.9 \\
\hline \multicolumn{3}{|l|}{ Dysphagia } \\
\hline $0-1$ & 52 & 63.4 \\
\hline$\geq 2$ & 30 & 36.6 \\
\hline
\end{tabular}

Abbreviations: $\mathrm{N}$, number of patients; SD, standard deviation; ECOG, Eastern Cooperative Oncology Group; Hb, hemoglobin.

and squamous cell carcinoma ( $\mathrm{n}=74,90.2 \%)$. Approximately $69.5 \%(n=57)$ patients were recorded with stage III-IV tumors with tumor locations as follows: upper-third (19/82, $23.1 \%)$, middle-third $(37 / 82,45.1 \%)$, and lower-third $(13 / 82,15.9 \%)$. A majority of tumors were more than $5 \mathrm{~cm}$ in length $(72.0 \%)$.

\section{Treatment compliance and tumor response to CCRT}

All patients completed the first cycle of chemotherapy. Three patients refused the second cycle of chemotherapy, one patient developed refractory peritonitis during treatment and the other two got fever after occurrence of grade 4 leukopenia and grade 3 thrombocytopenia. These patients also gave up radiation. Eleven (13.4\%) patients required dose reduction in the second cycle of chemotherapy for hematological toxicity, and the actual dose of PTX and CDDP was reduced to 105 and $25 \mathrm{mg} / \mathrm{m}^{2}$, respectively. Approximately 71 (86.6\%) patients completed radiation, including four patients with radiation delay. A total of 66 (80.5\%) patients finished CCRT 
Table 2 Tumor characteristics

\begin{tabular}{|c|c|c|}
\hline \multirow[t]{2}{*}{ Characteristics } & \multicolumn{2}{|c|}{$\mathbf{N}=\mathbf{8 2}$} \\
\hline & $\overline{\mathbf{N}}$ & Percentage \\
\hline \multicolumn{3}{|l|}{ T stage } \\
\hline TI & 2 & 2.4 \\
\hline $\mathrm{T} 2$ & 4 & 4.8 \\
\hline T3 & 54 & 66.0 \\
\hline $\mathrm{T} 4$ & 22 & 26.8 \\
\hline \multicolumn{3}{|l|}{$\mathrm{N}$ stage } \\
\hline No & 28 & 34.1 \\
\hline NI & 54 & 65.9 \\
\hline \multicolumn{3}{|l|}{ M stage } \\
\hline MO & 74 & 90.2 \\
\hline MI & 8 & 9.8 \\
\hline \multicolumn{3}{|l|}{ Clinical stage (AJCC 2002) } \\
\hline Stage I & 2 & 2.4 \\
\hline Stage II & 23 & 28.0 \\
\hline Stage III & 49 & 59.8 \\
\hline Stage IV & 8 & 9.8 \\
\hline \multicolumn{3}{|l|}{ Tumor location } \\
\hline Upper-third & 19 & 23.1 \\
\hline Middle-third & 37 & 45.1 \\
\hline Lower-third & 13 & 15.9 \\
\hline Multisection & 12 & 14.7 \\
\hline Unknown & I & 1.2 \\
\hline \multicolumn{3}{|l|}{ Histology on biopsy } \\
\hline Squamous cell carcinoma & 74 & 90.2 \\
\hline Adenocarcinoma & 6 & 7.3 \\
\hline Undifferentiated & 2 & 2.5 \\
\hline \multicolumn{3}{|l|}{ Histological differentiation } \\
\hline Well differentiated & 10 & 12.2 \\
\hline Fairly differentiated & 20 & 24.4 \\
\hline Poorly differentiated & 49 & 59.7 \\
\hline Unknown & 3 & 3.7 \\
\hline \multicolumn{3}{|l|}{ Tumor length $(\mathrm{cm})$} \\
\hline Average (SD, min-max) & \multicolumn{2}{|c|}{$6.46(2.46,2.46-15.0)$} \\
\hline$<5$ & 23 & 28.0 \\
\hline$\geq 5$ & 59 & 72.0 \\
\hline CT scan & 80 & 97.6 \\
\hline Echoendoscopy & 54 & 65.9 \\
\hline Barium swallow & 73 & 89.0 \\
\hline
\end{tabular}

Notes: Upper, including cervical and upper thoracic portion; middle, midthoracic portion; lower, including lower thoracic and distal esophagus.

Abbreviations: N, number of patients; SD, standard deviation; AJCC, American Joint Committee on Cancer; CT, computed tomography.

on schedule, including $55(67.1 \%)$ patients in whom treatment regimen was not changed.

A total of 81 patients were eligible for response evaluation, which was done after 4 weeks following the last radiotherapy session. Twenty-nine patients were considered to have had a complete response (CR), resulting in a $35.8 \% \mathrm{CR}$ rate, and 25 patients experienced no treatment effect (including 18 stable diseases and seven in progression). At the end of the last follow-up, 55 patients experienced disease recurrence. Primary recurrent sites included the following: 34 locoregional and local residual disease, 15 distant, and six in both sites.

\section{Severe acute and late toxicities}

The grade $\geq 3$ acute toxicity profile of CCRT is listed in Table 3. Acute toxicity reactions were assessed in all 82 patients. The most common hematologic toxicity was leukopenia, with $15(18.3 \%)$ patients and ten (12.2\%) patients having grade 3 and 4 leukopenia, respectively. Most patients recovered by using G-CSF. Grade $\geq 3$ thrombocytopenia was reported in three $(3.6 \%)$ patients and six (7.3\%) patients experienced grade $\geq 3$ anemia. Twenty-eight patients got esophagitis during the treatment, including five $(6.1 \%)$ patients and two $(2.4 \%)$ patients with grade 3 and 4 esophagitis, respectively. Other main grade $\geq 3$ nonhematologic toxicities included dysphagia (6.1\%), nausea/vomiting $(3.7 \%)$, mucositis $(2.4 \%)$, and diarrhea (4.9\%). One patient died of a fistula 0.97 months after the completion of treatment, and no cardiac toxicities or hypersensitivity reactions and alopecia related to PTX were reported. In terms of late toxicity, $12(14.6 \%)$ patients got esophageal stenosis and six (7.3\%) patients experienced radiation-related pneumonitis. Severe late radiation-associated toxicities affecting skin and heart were rare. In general, the regimen was well tolerated.

\section{Survival and prognostic analysis}

As shown in Figure 2, the median follow-up and OS of the overall population were 20.4 months (range, 0.97-67.4 months) and 26.9 months (95\% CI, 23.2-30.6), respectively. The 2-year OS rate for stage I-II and III-IV was $76.0 \%$ and $38.6 \%$, respectively. The median PFS

Table 3 Grade $\geq 3$ acute toxicities of concurrent chemoradiotherapy

\begin{tabular}{llll}
\hline Factor & N (\%) & & \\
\cline { 2 - 4 } & Grade 3 & Grade 4 & Grade 5 \\
\hline Acute & & & \\
$\begin{array}{l}\text { Hematologic toxicity } \\
\quad \text { Leukocytopenia }\end{array}$ & $\mathrm{I} 5(18.3)$ & $\mathrm{I} 0(\mathrm{I} 2.2)$ & - \\
$\quad$ Anemia & $6(7.3)$ & - & - \\
$\quad$ Thrombocytopenia & $2(2.4)$ & $\mathrm{I}(\mathrm{I} .2)$ & - \\
Nonhematologic toxicity & & & \\
$\quad$ Esophagitis & $5(6.1)$ & $2(2.4)$ & - \\
$\quad$ Dysphagia & $4(4.9)$ & $\mathrm{I}(\mathrm{I} .2)$ & - \\
$\quad$ Mucositis & $2(2.4)$ & - & - \\
$\quad$ Diarrhea & $4(4.9)$ & - & - \\
$\quad$ Nausea/vomiting & $3(3.7)$ & - & - \\
$\quad$ Astriction & $\mathrm{I}(\mathrm{I} .2)$ & - & - \\
$\quad$ Neurological/neuropathy & $\mathrm{I}(\mathrm{I} .2)$ & - & - \\
Treatment-related death & - & - & $\mathrm{I}(\mathrm{I} .2)$ \\
\hline Abbrevation: N number &
\end{tabular}

Abbreviation: $\mathrm{N}$, number of patients. 

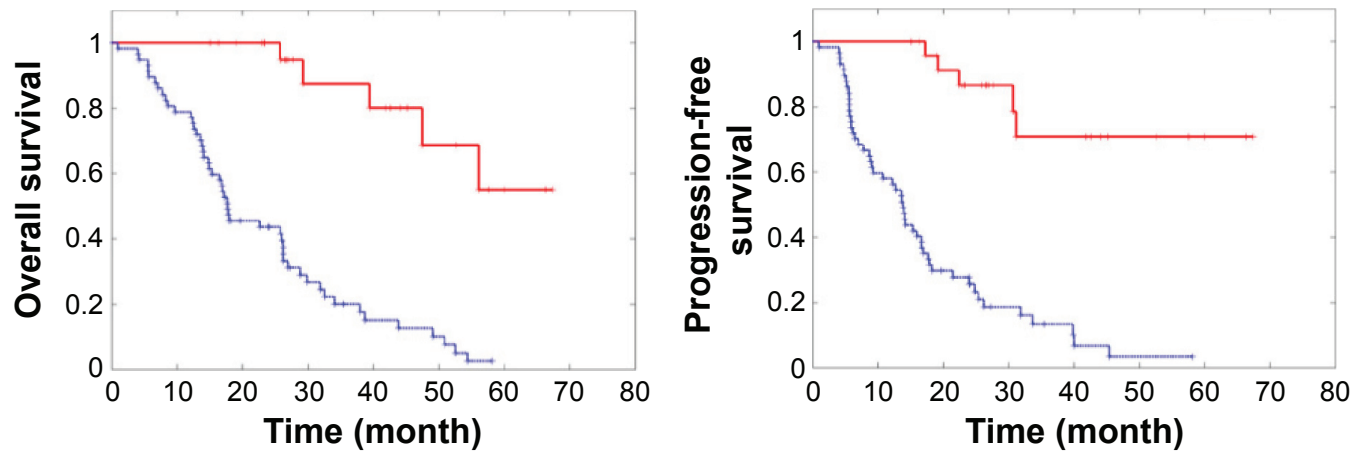

- Stage: I-II - Stage: III-IV

Figure 2 Overall survival and progression-free survival for the elderly esophageal cancer patients.

of the overall population was 18.2 months (95\% CI, 11.583-24.817), and the 2-year PFS rate for stage I-II and III-IV was $64.0 \%$ and $21.2 \%$, respectively. Univariate analyses were performed to assess the predictive capability of each variable (Table 4). The results suggested that several covariates were significantly associated with the OS: T stage ( $P=0.001)$, N stage $(P=0.000), \mathrm{M}$ stage $(P=0.021)$, clinical stage $(P=0.000)$, Charlson comorbidity score $(P=0.002)$, dysphagia $(P=0.013)$, clinical response $(P=0.001)$, ECOG PS $(P=0.032)$, and albumin $(P=0.001)$. The variables significantly associated with the PFS were T stage $(P=0.000)$, $\mathrm{N}$ stage $(P=0.000)$, clinical stage $(P=0.000)$, Charlson comorbidity score $(P=0.015)$, dysphagia $(P=0.006)$, clinical response $(P=0.000)$, and albumin $(P=0.003)$.

To identify independent prognostic factors, the factors that were found to be significant on univariate analysis were subjected to multivariate analysis. Multivariate analysis revealed that clinical stage ( $P$-value was 0.042 and 0.024 , respectively) was the independent factor affecting OS and PFS in elderly patients, and CR rate $(P=0.054)$ had statistical significance with PFS (Table 5).

\section{Discussion}

In this study, we presented a large cohort of elderly esophageal cancer patients treated with CCRT using PTX plus CDDP with curative intent. Our results showed that the median OS and PFS time were 26.9 and 18.2 months, with the 2-year OS rate of $76.0 \%$ and $38.6 \%$ for stage I-II and III-IV, respectively. These survival results seemed comparable with RTOG 0113 trial $^{20}$ and a series of contemporary randomized studies of patients from all age groups undergoing definitive chemoradiation. ${ }^{12,21-23}$ In RTOG 0113, 35 patients were enrolled for the treatment of induction chemotherapy followed by chemoradiotherapy with PTX and CDDP for localized esophageal cancer, and their results showed that the median survival time was 14.9 months and 1- and 2-year OS rates were $69 \%$ and $37 \%$, respectively. In another Phase II prospective clinical trial which investigated the efficacy and the safety of a 3-week schedule of PTX plus CDDP combined with concurrent radiotherapy for esophageal squamous cell cancer, ${ }^{12}$ the results showed that the overall median survival time was 28.5 months, the PFS was 14.7 months, and 1- and 2 -year survival rates were $75 \%$ and $54 \%$, respectively. Both these trials enrolled relatively nonelder patients (median age was 66 and 58 years, respectively). In our report, all patients were aged 70 years or older, and patients aged $\geq 75$ years accounted for more than a half of the overall population. Although two patients with $\mathrm{T}_{1}$ stage were enrolled in our analysis, almost $70 \%$ of our cohort were in stages III-IV, which was also comparable with Tang et al's ${ }^{12}$ report mentioned earlier (72.3\% for stage III-IV). In 2015, Servagi-Vernat et al also conducted a Phase II clinical trial to evaluate the efficacy of CCRT comprising a single platinum-based agent combined with radiotherapy in patients $\geq 75$ years of age with esophageal cancer, and their results showed that the 3-year OS rate and 2 -year disease-free survival rate were $22.2 \%$ and $38 \%$, respectively. They concluded that elderly patients should not be excluded from CCRT and that the elderly might be able to tolerate the treatment with acceptable acute toxicities. They also suggested that the therapeutic ratio or locoregional control might be improved by increasing the radiotherapy dose or by testing new radiosensitizer agents. ${ }^{24}$

In general, the toxicities of the combined therapy were tolerable in our study. The main grade $\geq 3$ toxicity was leukopenia, in $15(18.3 \%)$ and ten $(12.2 \%)$ patients with grade 3 and 4 leukopenia, respectively. Most of these elderly patients were treated by using G-CSF, which was monitored weekly during the treatment course for acute toxicity. Compared with 
Table 4 Univariate analysis demonstrating factors associated with OS and PFS

\begin{tabular}{|c|c|c|c|c|c|}
\hline Factor & Cases (n) & OS P-value & HR (95\% Cl) & PFS P-value & HR (95\% Cl) \\
\hline Age (years) & & 0.383 & $0.864(0.632-1.199)$ & 0.342 & $0.852(0.6 \mathrm{II}-\mathrm{I} .186)$ \\
\hline $70 \leq$ age $<75$ & 39 & & & & \\
\hline $75 \leq$ age $<80$ & 21 & & & & \\
\hline Age $\geq 80$ & 22 & & & & \\
\hline Sex & & 0.256 & $0.647(0.305-1.372)$ & 0.243 & $0.639(0.302-1.355)$ \\
\hline Female & 15 & & & & \\
\hline Male & 67 & & & & \\
\hline ECOG PS & & 0.032 & $2.072(1.065-4.033)$ & 0.122 & $1.664(0.873-3.174)$ \\
\hline $0-1$ & 63 & & & & \\
\hline 2 & 19 & & & & \\
\hline Weight loss & & 0.671 & I.I $36(0.630-2.048)$ & 0.979 & $1.008(0.562-1.808)$ \\
\hline$\leq 10 \%$ & 57 & & & & \\
\hline$>10 \%$ & 25 & & & & \\
\hline Charlson comorbidity score & & 0.002 & $2.685(1.431-5.037)$ & 0.015 & $2.091(1.153-3.791)$ \\
\hline $0-1$ & 27 & & & & \\
\hline$\geq 2$ & 55 & & & & \\
\hline T stage & & 0.001 & $2.196(1.37 I-3.520)$ & 0.000 & $2.518(1.549-4.091)$ \\
\hline $\mathrm{TI}$ & 2 & & & & \\
\hline $\mathrm{T} 2$ & 4 & & & & \\
\hline T3 & 54 & & & & \\
\hline $\mathrm{T} 4$ & 22 & & & & \\
\hline $\mathrm{N}$ stage & & 0.000 & $3.733(1.860-7.491)$ & 0.000 & $3.892(1.937-7.818)$ \\
\hline No & 28 & & & & \\
\hline $\mathrm{NI}$ & 54 & & & & \\
\hline M stage & & 0.021 & $2.823(1.169-6.816)$ & 0.118 & $1.986(0.84 \mid-4.692)$ \\
\hline Mo & 74 & & & & \\
\hline MI & 8 & & & & \\
\hline Clinical stage & & 0.000 & $9.138(3.590-23.262)$ & 0.000 & 9.491 (3.747-24.044) \\
\hline I-II & 25 & & & & \\
\hline III-IV & 57 & & & & \\
\hline Tumor location & & 0.985 & $0.997(0.762-1.306)$ & 0.846 & $0.974(0.745-1.272)$ \\
\hline Upper-third & 19 & & & & \\
\hline Middle-third & 37 & & & & \\
\hline Lower-third & 13 & & & & \\
\hline Multi + unknown & 13 & & & & \\
\hline Differentiation & & 0.520 & I.I34 (0.773-I.662) & 0.567 & I.II 2 (0.774-I.598) \\
\hline Well & 10 & & & & \\
\hline Fairly & 20 & & & & \\
\hline Poorly & 49 & & & & \\
\hline Unknown & 3 & & & & \\
\hline Tumor length $(\mathrm{cm})$ & & 0.098 & I.70I (0.907-3.189) & 0.104 & I.68I (0.899-3.I43) \\
\hline$<5$ & 23 & & & & \\
\hline$\geq 5$ & 59 & & & & \\
\hline Albumin $(\mathrm{g} / \mathrm{L})$ & & 0.001 & $3.782(1.675-8.539)$ & 0.003 & 3.448 (I.54I-7.7I7) \\
\hline$\geq 30$ & 75 & & & & \\
\hline$<30$ & 7 & & & & \\
\hline Hemoglobin $(g / L)$ & & 0.091 & $1.424(0.945-2.148)$ & 0.279 & I.256 (0.83 I-I.898) \\
\hline$\geq 10$ & 55 & & & & \\
\hline $8 \leq \mathrm{Hb}<10$ & 18 & & & & \\
\hline$<8$ & 9 & & & & \\
\hline Dysphagia & & 0.013 & $1.967(1.156-3.348)$ & 0.006 & $2.107(1.237-3.588)$ \\
\hline $0-1$ & 52 & & & & \\
\hline$\geq 2$ & 30 & & & & \\
\hline Clinical response & & 0.001 & $3.305(1.66 \mathrm{I}-6.578)$ & 0.000 & 3.899 (1.958-7.762) \\
\hline$C R$ & 29 & & & & \\
\hline Non-CR & 53 & & & & \\
\hline
\end{tabular}

Abbreviations: $n$, number of patients; OS, overall survival; PFS, progression-free survival; $\mathrm{HR}$, hazard ratio; $\mathrm{Cl}$, confidence interval; $\mathrm{CR}$, complete response; $\mathrm{ECOG} \mathrm{PS}$, Eastern Cooperative Oncology Group performance status; $\mathrm{Hb}$, hemoglobin. 
Table 5 Multivariate analysis of prognostic factors for patients with elderly esophageal cancer

\begin{tabular}{|c|c|c|c|}
\hline Endpoint & Factor & $P$-value & HR (95\% Cl) \\
\hline \multirow[t]{9}{*}{ OS } & T stage & 0.604 & $0.83 \mid(0.4|4-| .67 \mid)$ \\
\hline & $\mathrm{N}$ stage & 0.533 & I.487 (0.427-5. 175$)$ \\
\hline & M stage & $0.84 I$ & I.III (0.396-3.114) \\
\hline & Clinical stage & 0.042 & $4.98 \mid(1.062-23.352)$ \\
\hline & $\begin{array}{l}\text { Charlson comorbidity } \\
\text { score }\end{array}$ & 0.089 & $1.967(0.903-4.285)$ \\
\hline & Dysphagia & 0.573 & I.203 (0.634-2.282) \\
\hline & Clinical response & 0.137 & $1.756(0.836-3.688)$ \\
\hline & ECOG PS & 0.286 & $1.510(0.708-3.218)$ \\
\hline & Albumin & 0.373 & $1.773(0.504-6.24 I)$ \\
\hline \multirow[t]{7}{*}{ PFS } & T stage & 0.660 & $0.862(0.445-1.670)$ \\
\hline & $\mathrm{N}$ stage & 0.755 & $1.213(0.362-4.066)$ \\
\hline & Clinical stage & 0.024 & 5.988 (1.267-28.299) \\
\hline & $\begin{array}{l}\text { Charlson comorbidity } \\
\text { score }\end{array}$ & 0.073 & $1.932(0.940-3.972)$ \\
\hline & Dysphagia & 0.345 & $1.332(0.735-2.415)$ \\
\hline & Clinical response & 0.054 & $2.07 \mid(0.986-3.905)$ \\
\hline & Albumin & 0.746 & $1.213(0.377-3.905)$ \\
\hline
\end{tabular}

Abbreviations: OS, overall survival; PFS, progression-free survival; HR, hazard ratio; Cl, confidence interval; ECOG PS, Eastern Cooperative Oncology Group performance status.

the TP arm of RTOG 0113 trial in which the radiation dose was $50.4 \mathrm{~Gy} / 28 \mathrm{Fx},{ }^{20}$ the grade 3 and 4 adverse reactions of blood/bone marrow occurred in $40 \%$ (14/35) and $28.6 \%$ $(10 / 35)$ of the cases, respectively; and the treatment-related death was $6 \%$. Traditionally, elderly patients were considered to have less reserve of body function when compared with young patients, and our results indicated that with proper application of G-CSF, elderly patients could also undergo definitive treatment course without having a severe hematologic toxicity. The rate of severe esophagitis in our study was high compared with the results of Tang et al. ${ }^{12}$ Twenty-eight (34.1\%) patients in our study got esophagitis, including five $(6.1 \%)$ and two $(2.4 \%)$ patients with grade 3 and 4 , respectively; while in their report, only two patients suffered from grade 3 esophagitis and none had grade 4 esophageal dysfunction. Possible factors causing the high rate in our study are as follows: 1) a different radiation delivery schedule was used in their trial, $21 \%$ patients were given with a combination of conventional fractionation of $1.8 \mathrm{~Gy} /$ Fx and late-course accelerated hyperfractionated (LCAF) in a second course; 2) $72 \%$ patients in our analysis had $\geq 5 \mathrm{~cm}$ tumor, and tumor length has been confirmed as a significant prognostic factor for esophagitis in chest irradiation; ${ }^{25,26} 3$ ) total radiation dose in this study was $60 \mathrm{~Gy}$ as planned, and $86.6 \%$ elderly patients completed the radiation course. In 2007, we also did a Phase II clinical trial in our cancer center to investigate the toxicity of TP regime with $60 \mathrm{~Gy} / 30 \mathrm{Fx}$ radiotherapy for nonelderly esophageal cancer patients and showed comparable toxicities with this cohort. Nowadays, CCRT with 50.4 Gy is the standard treatment regimen for locally advanced esophageal cancer based on the results of RTOG $9405 ;^{8}$ this trial was designed to investigate whether high-dose irradiation in the setting of CCRT could achieve better survival results and local/regional control than 50.4 Gy CCRT. The results showed that higher radiation dose did not increase survival or local/regional control, and a higher treatment-related mortality rate was observed in the highdose arm. But, interpretations about the results of RTOG 9405 trial were different; although, more treatment-related deaths in the 9405 trial occurred in the high-dose arm than in the 50.4 Gy arm (11 vs 2), seven of these eleven treatmentrelated deaths occurred before the dose of 50.4 Gy for unclear reasons. Therefore, more deaths were not as a result of high-dose radiation therapy, and our results also showed that only one patient suffered from treatment-related death (esophageal fistula). In the present study, we also confirmed that clinical stage was a strong prognostic factor in elderly patients, as shown in Table 5. A clinical response rate of CR had an approximately statistical significance with PFS; these findings were consistent with the results conducted by Tougeron et al. ${ }^{16}$ Their analysis revealed that factors of clinical CR, radiation dose, and Charlson score were independent prognostic factors with survival.

In conclusion, elderly patients (70 years or older) could benefit from definitive CCRT containing PTX, but attention should be paid to the relatively high incidence of toxicities. Further prospective studies in large cohorts of elderly esophageal cancer patients are highly warranted to confirm the findings in our report.

\section{Acknowledgment}

There was no funding support for this study. We thank Ruifei Xie for his help with translation and proofreading.

\section{Disclosure}

Tao Song and Xuebang Zhang are listed as co first authors. The authors report no conflicts of interest in this work.

\section{References}

1. Siegel R, Naishadham D, Jemal A. Cancer statistics for Hispanics/ Latinos, 2012. CA Cancer J Clin. 2012;62(5):283-298.

2. Siegel R, Ma J, Zou Z, Jemal A. Cancer statistics, 2014. CA Cancer J Clin. 2014;64(1):9-29.

3. Nallapareddy S, Wilding GE, Yang G, Iyer R, Javle M. Chemoradiation is a tolerable therapy for older adults with esophageal cancer. Anticancer Res. 2005;25(4):3055-3060.

4. Chino O, Makuuchi H, Machimura T, et al. Treatment of esophageal cancer in patients over 80 years old. Surg Today. 1997;27(1):9-16. 
5. Mohansingh MP. Mortality of oesophagal surgery in the elderly. $B r J$ Surg. 1976;63(8):579-580.

6. Poon RT, Law SY, Chu KM, Branicki FJ, Wong J. Esophagectomy for carcinoma of the esophagus in the elderly: results of current surgical management. Ann Surg. 1998;227(3):357-364.

7. Cooper JS, Guo MD, Herskovic A, et al. Chemoradiotherapy of locally advanced esophageal cancer: long-term follow-up of a prospective randomized trial (RTOG 85-01). Radiation Therapy Oncology Group. JAMA. 1999;281(17):1623-1627.

8. Minsky BD, Pajak TF, Ginsberg RJ, et al. INT 0123 (Radiation Therapy Oncology Group 94-05) phase III trial of combined-modality therapy for esophageal cancer: high-dose versus standard-dose radiation therapy. J Clin Oncol. 2002;20(5):1167-1174.

9. Milas L, Milas MM, Mason KA. Combination of taxanes with radiation: preclinical studies. Semin Radiat Oncol. 1999;9(2 Suppl 1):12-26.

10. Ilson DH. New developments in the treatment of esophageal cancer. Curr Oncol Rep. 2002;4(3):213-221.

11. Ilson DH, Wadleigh RG, Leichman LP, Kelsen DP. Paclitaxel given by a weekly 1 -h infusion in advanced esophageal cancer. Ann Oncol. 2007;18(5):898-902.

12. Tang HR, Ma HF, An SM, et al. A phase II study of concurrent chemoradiotherapy with paclitaxel and cisplatin for inoperable esophageal squamous cell carcinoma. Am J Clin Oncol. Epub April 11, 2014.

13. Zhang P, Xie CY, Wu SX. Concurrent chemoradiation with paclitaxel and platinum for locally advanced esophageal cancer. Zhonghua Zhong Liu Za Zhi. 2007;29(10):773-777. Chinese.

14. Takeuchi S, Ohtsu A, Doi T, et al. A retrospective study of definitive chemoradiotherapy for elderly patients with esophageal cancer. Am J Clin Oncol. 2007;30(6):607-611.

15. Feng JF, Huang Y, Chen L, Zhao Q. Prognostic analysis of esophageal cancer in elderly patients: metastatic lymph node ratio versus 2010 AJCC classification by lymph nodes. World J Surg Oncol. 2013;11: 162.

16. Tougeron D, Di Fiore F, Thureau S, et al. Safety and outcome of definitive chemoradiotherapy in elderly patients with oesophageal cancer. Br J Cancer. 2008;99(10):1586-1592.
17. Atkinson M. Diseases of the alimentary system. Dysphagia. Br Med J. 1977;1(6053):91-93.

18. Charlson ME, Sax FL, MacKenzie CR, Braham RL, Fields SD, Douglas RG Jr. Morbidity during hospitalization: can we predict it? J Chronic Dis. 1987;40(7):705-712.

19. Li G, Hu W, Wang J, et al. Phase II study of concurrent chemoradiation in combination with erlotinib for locally advanced esophageal carcinoma. Int J Radiat Oncol Biol Phys. 2010;78(5):1407-1412.

20. Ajani JA, Winter K, Komaki R, et al. Phase II randomized trial of two nonoperative regimens of induction chemotherapy followed by chemoradiation in patients with localized carcinoma of the esophagus: RTOG 0113. J Clin Oncol. 2008;26(28):4551-4556.

21. Zhao T, Chen H, Zhang T. Docetaxel and cisplatin concurrent with radiotherapy versus 5-fluorouracil and cisplatin concurrent with radiotherapy in treatment for locally advanced oesophageal squamous cell carcinoma: a randomized clinical study. Med Oncol. 2012;29(5):3017-3023.

22. Nishimura Y, Mitsumori M, Hiraoka M, et al. A randomized phase II study of cisplatin/5-FU concurrent chemoradiotherapy for esophageal cancer: short-term infusion versus protracted infusion chemotherapy (KROSG0101/JROSG021). Radiother Oncol. 2009;92(2):260-265.

23. Conroy T, Galais MP, Raoul JL, et al. Definitive chemoradiotherapy with FOLFOX versus fluorouracil and cisplatin in patients with oesophageal cancer (PRODIGE5/ACCORD17): final results of a randomised, phase 2/3 trial. Lancet Oncol. 2014;15(3):305-314.

24. Servagi-Vernat S, Crehange G, Roullet B, et al. Phase II study of a platinum-based adapted chemotherapy regimen combined with radiotherapy in patients 75 years and older with esophageal cancer. Drugs Aging. 2015;32(6):487-493.

25. Gu T, Hua HX, Fu ZZ, et al. Multi-factor analysis of radiation-induced esophagitis in three-dimensional conformal radiotherapy for non-small cell lung cancer. Zhonghua Zhong Liu Za Zhi. 2011;33(11):868-871. Chinese.

26. Eloubeidi MA, Desmond R, Arguedas MR, Reed CE, Wilcox CM. Prognostic factors for the survival of patients with esophageal carcinoma in the U.S.: the importance of tumor length and lymph node status. Cancer. 2002;95(7):1434-1443.
OncoTargets and Therapy

\section{Publish your work in this journal}

OncoTargets and Therapy is an international, peer-reviewed, open access journal focusing on the pathological basis of all cancers, potential targets for therapy and treatment protocols employed to improve the management of cancer patients. The journal also focuses on the impact of management programs and new therapeutic agents and protocols on

\section{Dovepress}

patient perspectives such as quality of life, adherence and satisfaction The manuscript management system is completely online and includes a very quick and fair peer-review system, which is all easy to use. Visit http://www.dovepress.com/testimonials.php to read real quotes from published authors. 